\title{
JAIR BOLSONARO E OS POLÍTICOS EVANGÉLICOS ${ }^{1}$ Jair Bolsonaro y los políticos evangélicos
}

\author{
Ariel GOLDSTEIN \\ Universidade de Buenos Aires, Buenos Aires, Argentina \\ arielgoldstein@hotmail.com \\ https://orcid.org/0000-0002-0105-4428 (iD
}

A lista completa com informações dos autores está no final do artigo

\section{OS EVANGÉLICOS NA POLÍTICA DO BRASIL}

"Os evangélicos são a chave" para tecer relações com o Governo de Bolsonaro, disse o primeiro-ministro Benjamin Netanyahu a Yossi Shelley, o embaixador de Israel no Brasil. ${ }^{2}$ A aliança entre os governos de ambos os países se encontra cimentada sobre a união das coletividades religiosas e a promessa do traslado da embaixada do Brasil em Israel de Tel Aviv a Jerusalém. A organização brasileira Comunidade Internacional BrasilIsrael (CIBI), que busca aproximar ambos os países, é presidida pela pastora da lgreja do Evangelho Quadrangular de Belo Horizonte, Janícia Silva. Quem logo foi nomeada pelo Governo de Bolsonaro como secretária adjunta de Cultura. ${ }^{3}$ Durante o Governo de Bolsonaro, os vínculos políticos com Israel se converteram numa carta de ascensão dos evangélicos no Estado.

\footnotetext{
${ }^{1}$ Tradução realizada por Flavio Pereira (e-mail: poliglotta@gmail.com; orcid: https://orcid.org/0000-00015922-6360), doutor em Língua Espanhola e Literaturas Espanhola e Hispano-americana pela USP e professor da área de Espanhol do Colegiado de Letras Português-Espanhol/Inglês da Unioeste, campus de Foz do Iguaçu. Texto original publicado em: GOLDSTEIN, Ariel Alejandro. Jair Bolsonaro y los políticos evangélicos. In: Poder Evangélico: como os grupos religiosos estão dominando a política na América. Buenos Aires: Marea, 2020.

2 Marcelo Ninio: "Entrevista Yossi Shelley: Houve quatro conquistas para Israel na visita”, O Globo, p. 24 (4.4.2019).

${ }^{3}$ Caio Menezes: "Saiba quem é a reverenda Jane Silva, número 2 de Regina Duarte na Cultura", Jovem Pan (23.1.2020).
} 
Nos últimos anos, o avanço das igrejas evangélicas nas periferias das grandes cidades moldou a política do Brasil, especialmente no norte, onde têm maior presença. ${ }^{4}$ Durante a década de 90 , num contexto de crise econômica, a população evangélica passou de 13 a 26 milhões de pessoas. A mobilidade social que se produziu durante os anos dos governos de Lula e Dilma, quando mais de 39 milhões de pessoas ingressaram na chamada "classe C" entre 2003 e $2011,{ }^{5}$ permitiu que novas formas de subjetividade como expressão de uma mudança na condição econômica se encontrassem com a chamada "teologia da prosperidade" promovida pelos pastores. Atualmente, segundo a consultora Datafolha, $31 \%$ da população se identificaria com o culto evangélico. ${ }^{6}$

Em sua primeira viagem internacional ao Brasil na Jornada Mundial da Juventude de 2013, à qual compareceram milhões de personas, o Papa Francisco estabeleceu contrapontos com o discurso moralizante e conservador dos pastores evangélicos, a respeito da condenação destes últimos à homossexualidade. ${ }^{7}$ Francisco teve tensões com o Governo direitista de Jair Bolsonaro por causa do tema do Amazonas. Na resposta à pretensão do Vaticano de organizar um Sínodo do Amazonas para denunciar os problemas da mudança climática, o general Augusto Heleno, chefe de Gabinete de Segurança Institucional do Governo brasileiro, assinalou que iriam "fazer inteligência" para espiar esta atividade. Isto reforça uma situação em que o Governo brasileiro se coloca ao lado dos evangélicos e Francisco ficou no lado oposto. O chanceler do Governo do Brasil, Ernesto Araújo, declarou recentemente que a Igreja católica perde fiéis por "aderir ao neomarxismo".

Uma das maiores igrejas neopentecostais, a Igreja Universal do Reino de Deus (IURD), foi iniciada no Brasil pelo predicador e bispo Edir Macedo em 1977. Com uma estratégia de expansão dos templos, lançamento de livros, CDs de música, e compra de meios como o Grupo Record, foi convertendo-se em uma das maiores congregações evangélicas do mundo e com a organização mais sofisticada. A partir de 2008, a Record se consolidou como a segunda maior rede de televisão do país, quando chegou a $17 \%$ da audiência nacional entre as sete da manhã e a meia-noite. ${ }^{8}$

\footnotetext{
${ }^{4}$ Anna Virginia Balloussier: "Quando os evangélicos serão maioria no Brasil", Café da Manhã, Folha de São Paulo, podcast (13.1.2020).

5 Jean Tible: “¿Una nueva clase media en Brasil? El lulismo como fenómeno político-social”, Nueva Sociedad, núm. 243, pp. 4-17 (2013).

6 Érica Fraga: "Crises econômicas elevam o número de fiéis evangélicos", Folha de São Paulo (17.12.2019).

${ }^{7}$ Almeida, R. de (2013). A visita de Francisco e a abertura do compasso. Estudos de religião, 27(2), 297-303.

${ }^{8}$ Mauro Porto, Daniela Neves e Bárbara Lima: "Crise hegemônica, ascensão da extrema direita e paralelismo político: Globo e Record nas eleições presidenciais de 2018", Revista Compolítica, vol. 10 (2020).
} 
A biografia de Edir Macedo, lançada em três tomos, assim como o seu livro Nos passos de Jesus e Orixás, Caboclos \& Guias. Deuses ou demônios? converteram-se em best sellers, alcançando os três milhões de vendas cada um. Este último livro enfrentou problemas com a justiça do Brasil por desenvolver um ataque aos cultos religiosos africanos, os quais qualifica como "seitas demoníacas". 9 Macedo desenvolveu uma estratégia engenhosa que consiste em atacar as religiões africanas e a umbanda para desprestigiá-las, enquanto absorve parte dos seus rituais, práticas e cultos para a IURD. ${ }^{10}$

O filme Nada a perder, sobre a biografia de Macedo, lançada em 2018, foi o filme mais visto do ano no Brasil. A IURD, cujo slogan "Pare de sofrer" se tornou famoso, possibilita a conversão de pessoas que se encontram com "dor" e "no fundo do poço", numa crise de identidade. ${ }^{11}$ A IURD iniciou suas atividades em Angola em 1992, e abriu mais de 230 templos nesse país, estando presente em 23 dos 55 países africanos. ${ }^{12}$

Em seu livro de 2008, Plano do Poder, Macedo indicava a estratégia de conquista política que iriam seguir os pastores: "Maquiavel definiu a política como 'a arte de governar e estabelecer o poder'. Sendo assim, do ponto de vista de Deus, com quem você acredita que Ele desejaria que estivesse esse poder e o domínio? Nas mãos de Seu povo ou não?". ${ }^{13}$ A igreja se encontra organizada segundo hierarquias que compreendem "bispos", "pastores" e "operários". Estes últimos são de vital importância, porque saem às ruas para "evangelizar", colocam-se nas grades das grandes igrejas, assistem aos pastores e conversam com os fieis: "Quando alguém chega à Igreja Universal, pela primeira vez, buscando auxílio, é atendido, na maioria das vezes, por um operário, que escuta sua história com atenção e procura encaminhar para a resolução do problema de alguma forma [...] Quando se é ascendido a operário, passa-se lidar com almas e se declara a guerra contra o diabo, que lutará com todas as suas armas para impedir que alguém seja liberado de sus garras", indica a Universal. ${ }^{14}$

\footnotetext{
9 "Justiça tenta suspender venda de livro do dono da Record", Ofuxico.com.br (9.11.2005).

10 "Apoio da Universal a políticos depende da conveniência do momento, diz autor", entrevista de Eduardo Sombini a Gilberto Nascimento, Ilustríssima Conversa, Folha de São Paulo, podcast (8.2.2020).

${ }^{11}$ Maria Lucia Pereira de Oliveira: "Aspectos Psicossociais da Conversão Religiosa. Um estudo de caso na Igreja Universal do Reino de Deus", dissertação de Mestrado em Ciências da Religião, Pontifícia Universidade Católica de Goiás (2006).

12 João Fellet: "Pastores da Universal em Angola rompem com Edir Macedo e pedem expulsão de bispos brasileiros", BBC News Brasil (29.11.2019).

${ }^{13}$ Anna Virginia Balloussier: "Sub-representados, evangélicos veem espaço para crescimento no Congresso", Folha de São Paulo (24.1.2020).

14 "Por que ser obreiro?", Obreiros Universal (6.9.2013).
} 
Os grupos evangélicos ingressaram na política nos anos 80 , apresentando cada vez mais candidatos a deputados. ${ }^{15}$ Foram um importante apoio da candidatura de Fernando Collor de Mello em 1989 em função de sua postura anticorrupção e sua mensagem messiânica antipartidária. Os católicos, por sua vez, eram vistos pelos pentecostais como parte de uma "aliança comunista" que apoiava o Lula. Edir Macedo temia os efeitos que pudesse provocar a plataforma reformista de Lula em 1989 sobre a TV Record, o principal meio de comunicação evangélico. ${ }^{16}$ A partir de 2003 , com a chegada do PT à presidência, estes grupos estabeleceram uma aliança pragmática com o Governo.

Marina Silva, a ex-ministra de Meio Ambiente no Governo de Lula até 2008, já havia angariado um bom desempenho entre este eleitorado nas eleições presidenciais de 2010, ao obter 19,5 milhões de votos com a fraca formação do Partido Verde. Na época desta eleição, os pastores Magno Malta e Marco Feliciano condicionaram o apoio evangélico a Dilma Rousseff a firmar uma carta onde a candidata a presidenta se comprometia a não impulsionar o aborto e a consensuar com eles questões referidas ao tema da homofobia. ${ }^{17}$ Por sua vez, durante a campanha correspondente a esta eleição, José Serra, o candidato do Partido da Socialdemocracia Brasileira (PSDB), havia desenvolvido una prédica religiosa e conservadora, acusando Rousseff de querer impulsionar o aborto. Em 2014, com 1.500.000 votos, o animador de televisão de TV Record, Celso Russomanno, candidato pelo Partido Republicano Brasileiro (PRB) a deputado por San Paulo, foi o mais votado do país. ${ }^{18}$

Durante os governos de Rousseff, os evangélicos tendiam a apoiá-la graças à presença no Governo do ministro da Pesca, o bispo da Igreja Universal do Reino de Deus (IURD), Marcelo Crivella. ${ }^{19}$ A eleição de Crivella como prefeito do Rio de Janeiro em 2016 foi a primeira em que um candidato cuja base política inicial foi o meio evangélico chegasse o poder pelos votos. ${ }^{20}$ Rousseff transferiu recursos estatais para o combate às drogas para

15 Fabio Lacerda: "Pentecostalismo, eleições e representação política no Brasil contemporâneo", tese doutoral, Universidade de São Paulo (2017).

16 Paul Freston: Evangelicals and Politics..., o. cit.

17 Janine Trevisan: "A Frente Parlamentar Evangélica: Força política no estado laico brasileiro", Numen, vol. 16, núm. 1 (2013).

18 Tiago Dantas, Danielo Fariello e Evandro Éboli: "Russomanno é o deputado mais votado do país", O Globo (6.10.2014).

19 Paulo de Tarso Lyra: "O destino do capital político", Correio Braziliense (3.10.2013).

${ }^{20}$ Ronaldo Almeida: O. cit. 
comunidades terapêuticas evangélicas, sem fiscalização nem controles, medida que foi questionada pelo Conselho Federal de Psicologia. ${ }^{21}$

O deputado Eduardo Cunha, eleito em fevereiro de 2015 como presidente da Câmara dos Deputados, promoveu o impeachment da Dilma e foi um membro importante da Frente Parlamentar Evangélica. 89\% da Frente Parlamentar Evangélica votou "sim" ao impeachment da Dilma Rousseff em 2016. ${ }^{22}$ O período de Cunha neste cargo expressou o desenvolvimento dos evangélicos no nivel político e uma cristalização de seu avanço na correlação de forças no Congresso. A liderança de Cunha sobre os deputados evangélicos se devia a seu vínculo com a Igreja Assembleia de Deus Madureira. ${ }^{23}$

Desde 2014, os principais políticos caíram em descrédito pelo manto de corrupção colocado sobretudo no sistema político pelo desdobramento da operação Lava Jato dirigida de Curitiba pelo juiz Sérgio Moro. Com este desprestígio generalizado da classe política e os devastadores efeitos da crise econômica sobre a vida social, assim como uma formidável crise na segurança pública, as bases populares, que haviam apoiado o Partido dos Trabalhadores (PT) por sus exitosas políticas de transferência de renda como o Bolsa Família, foram migrando rumo a outras opções. Estes aspectos reforçaram o poder dos pastores evangélicos como referências diante da queda dos principais líderes políticos. A deputada estadual por São Paulo do Partido Socialismo e Liberdade (PSOL), Mônica Seixas, descreve com agudeza esta penetração do evangelismo no mundo popular: "Entra na favela para ver o trabalho de base. O pastor dá remedios e comida. Faz com que o marido deixe de beber e de agredir. Visita o filho na prisão e promete à mãe que Deus vai libertá-lo. Uma relação de esperança que nós não criamos. E por isso o preço dos dogmas é completamente aceitável". ${ }^{24}$

Como "sociólogos selvagens", 25 percebendo cotidianamente as angústias populares, os pastores evangélicos foram dos primeiros a reconhecer o potencial eleitoral do excapitão do Exército Jair Bolsonaro, porque os fiéis se inclinavam para a sua candidatura nas igrejas, conforme assegurou numa entrevista o influente pastor da Igreja Vitória em Cristo, Silas Malafaia. ${ }^{26}$

21 “'Evangélicos querem mais espaço na política', diz socióloga”, Istoé Dinheiro (11.1.2020).

22 "Bancada evangelica mira 'direitos humanos', Folha de São Paulo (29.10.2017).

23 Ronaldo Almeida: O. cit.

$24 @$ MonicaSeixas (3.4.2019). Disponível em twitter.com/MonicaSeixas

25 Maristella Svampa e Sebastián Pereyra: “Entrevista a José Nun”, Cuestiones de Sociología, num. 14 (2016).

26 Thiago Prado e Daniela Pinheiro: "Lá em cima. Até onde vai Malafaia no governo Bolsonaro", Época (3.12.2018). 
O controvertido ataque recebido por Bolsonaro em Juiz de Fora, Minas Gerais, em setembro de 2018, entrava dentro de uma narrativa religiosa de triunfo, messianismo e redenção. Com vistas ao primeiro turno, nas igrejas evangélicas os fiéis vestiam a camiseta "Meu partido é o Brasil", que o candidato militar usava quando sofreu o atentado, pintada com manchas vermelhas que simbolizavam o ataque sofrido por Bolsonaro. ${ }^{27}$

Tanto Michelle Bolsonaro como o presidente constroem uma narrativa religiosa messiânica que entende a presidência, especialmente a partir da facada, como uma missão moral redentora e guiada por Deus. Sobre o atentado que sofreu o seu marido, a primeira dama assinalou: "O Senhor colocou paz em nosso coração. O que ia ser uma morte, converteu-se num milagre. Resgatou o patriotismo, resgatou uma nação, despertou uma igreja que rezou pela sua recuperação". ${ }^{28}$ A primeira dama torna manifesta sua fé evangélica, como parte da Igreja Batista Atitude, dirigida pelo pastor Josué Valandro Jr. Esta Igreja, localizada na privilegiada zona da Barra da Tijuca, Rio de Janeiro, conquista novos fiéis a partir da organização em células e conta com uma "comunidade terapêutica" para 120 pessoas e uma creche para 250 crianças.

Em junho de 2019, Bolsonaro se transformou no primeiro presidente em estar presente na $27^{a}$. Marcha de Jesus realizada em São Paulo, o evento evangélico mais importante do país. ${ }^{29} \mathrm{O}$ apóstolo Cezar Augusto, da Igreja Apostólica Fonte de Vida, orou pelo presidente e assegurou que "as mudanças já começaram [...] tenho a certeza de que o senhor vai seguir marchando por oito anos mais. O senhor é um homem de Deus. Com a coragem para declarar a Deus por cima de tudo". ${ }^{30} \mathrm{O}$ palco principal do ato foi ocupado pelo embaixador de Israel no Brasil, Yossi Shelley, que Bolsonaro apresentou como "um coronel do Exército israelense". O pastor Estevam Hernandes, da Igreja Renascer em Cristo, levantou a mão de Bolsonaro e disse:

Senhor Jesus, levantamos nossas mãos para abençoar nosso presidente, sua família, e te pedimos que diariamente lhes dê saúde, luz, inteligência e sabedoria. Libera-o de todos os males, guia-o, guarda-o, que o Senhor o levante e através da vida deste

${ }^{27}$ Anna Virginia Balloussier: “'Patriota' e 'da família', Bolsonaro recebe benção das lideranças evangélicas”, Folha de São Paulo (8.10.2018).

28 "Michelle: atentado contra Bolsonaro 'resgatou uma nação e despertou uma igreja"', Agencia Estado (27.3.2019).

${ }^{29}$ Ana Virginia Balloussier: "Marcha para Jesus tem divisor de águas com presidente 'messias", Folha de São Paulo (21.6.2019).

${ }^{30}$ Anna Virginia Balloussier y Joelmir Tavares: "Bolsonaro é ovacionado em Marcha para Jesus e fala em problemas de ética, moral e economia", Folha de São Paulo (20.6.2019). 
homem, este país se transforme. Pusemos sobre ele a benção do corpo de Cristo e as portas do inferno não prevalecerão.

O presidente, correspondendo às demandas deste setor, mencionou sua intenção de nomear ao Supremo Tribunal Federal um ministro que seja "terrivelmente evangélico". Por sua vez, manifestou o interesse por subsidiar a luz dos templos evangélicos. Outrossim, o presidente defendeu que o novo presidente da Agência Nacional de Cinema deveria ser um evangélico que conseguisse "recitar 200 versículos bíblicos, que tivesse os joelhos machucados de ajoelhar-se e que andasse com a Bíblia debaixo do braço". De acordo com as novas disposições tomadas por seu Governo, o teto de arrecadação para que uma igreja seja obrigada a declarar seus movimentos financeiros por dia, passou de 1,2 milhões de reais a 4,8 milhões. ${ }^{31}$

Ao manter uma guerra com o grande grupo de mídia Globo, Bolsonaro aproxima o Governo de novas elites midiáticas para manter a estabilidade. É o caso de Edir Macedo, o criador da Igreja Universal do Reino de Deus e dono da TV Record, que vê incrementado o seu poder e se converteu numa correia de transmissão entre o Governo e o eleitorado evangélico, com uma cobertura favorável ao presidente.

No momento da eleição de 2018 que consagrou Bolsonaro nas urnas, Lula, um grande "sociólogo selvagem" do Brasil, da prisão havia assinalado que se dedicava a observar os pastores evangélicos na televisão, ao considerar que tinham se transformado em atores fundamentais da vida social e política do país. ${ }^{32}$ Ao sair da prisão em Curitiba, o veterano líder declarou que seu partido precisa "aprender com os pastores" e que "eles falam bem e o que as pessoas querem ouvir"33. Por esse motivo, ordenou ao PT criar núcleos evangélicos em cada estado e argumenta que:

O pentecostal da prosperidade tem uma linguagem fácil para conversar com o povo. Porque está, de um lado, o autor de todos os problemas, que é o diabo, e toda a solução, que é Deus. Se não há solução, a culpa é da pessoa porque não tem fé. [...] Eles estão entrando na periferia, porque a fé do povo aumenta quando está desempregado e necessitado [...] Essa fé, do povo brasileiro, é muito grande e nós temos que respeitá-la. Em lugar de nos colocarmos contra, temos que saber como é que lidamos com essa nova forma de pensar do povo brasileiro. Inclusive de pensar a religião. [...] O que o PT tem que

\footnotetext{
31 Merval Pereira: "Muro ameaçado", O Globo (11.1.2020).

32 "Repórter detalha dia a dia de Lula na prisão", Café da Manhã, Folha de São Paulo, podcast (1.4.2019).

33 Mariana Carneiro: "A pedido de Lula, PT cria núcleos evangélicos nos estados para buscar apoio na base religiosa”, Folha de São Paulo (5.1.2020).
} 
entender é que essas pessoas estão na periferia, oferecendo às pessoas pobres uma saída espiritual. As pessoas estão isoladas na periferia, sem receber ajuda do Estado. Quem as recebem? Por um lado, o narcotraficante. Por outro, a Igreja evangélica, a Igreja católica. ${ }^{34}$

Um fenômeno significativo que se produz atualmente nas favelas do Brasil é a relação entre os evangélicos e os narcotraficantes. Entre estes últimos, quem adota a fé evangélica e se fazem chamar "traficantes de Jesus", perseguem aqueles que manifestam outras religiões ou espiritualidade, de tipo africano ou umbanda. Deste modo, deidades que são consideradas "satânicas" pelos evangélicos foram atacadas. Isto se vincula à importante presença dos pastores no serviço penitenciário, onde oferecem aos presos converter-se para obter a "salvação" e serviços de bem-estar que o Estado não provê. ${ }^{35}$

Considerando este contexto, o capítulo se propõe analisar a trajetória e agenda política dos principais líderes da Frente Parlamentar Evangélica. Neste sentido, serão analisados os líderes evangélicos com cargos políticos relevantes: Sóstenes Cavalcante, Hidekazu Takayama, Pastor Everaldo, Marco Feliciano e Silas Câmara. Como atores fundamentais durante a campanha eleitoral de 2018 e para a chegada ao Governo de Bolsonaro e sua continuidade, o setor evangélico está obtendo um protagonismo inédito no Congresso. Na medida em que continue o declínio na popularidade do presidente, estes setores aumentam proporcionalmente sua importância para a sustentabilidade do Governo.

Atualmente, a política exterior do Itamaraty com respeito à África é dirigida por deputados do bloco evangélico, o que mostra o imenso peso deste setor. Os deputados federais evangélicos presidem sete dos oito grupos do Congresso de amizade entre o Brasil e as nações africanas: "Hoje a África é o lugar de maior expansão do cristianismo no mundo, e isso merece minha especial atenção", destaca o influente pastor Marco Feliciano. ${ }^{36}$

Após a assunção do ex-capitão Jair Bolsonaro em janeiro de 2019, no momento da aparição de vários conflitos, motivados pelo aumento da importância política em jogo da Frente Parlamentar Evangélica (FPE) durante este período, definiu-se entre os distintos grupos que o pastor Silas Câmara, representante da igreja pentecostal Assembleia de Deus, assumisse a coordenação da FPE.

\footnotetext{
${ }^{34}$ Leonardo Sakamoto, Marco Britto e Marcos Sergio Silva: "Lula: PT deve olhar evangélico e periferia, que vive entre igreja e tráfico", UOL (27.1.2020).

35 José Cueto: “Traficantes de Jesús', los pandilleros evangélicos que atemorizan a las religiones afrobrasileñas en Brasil", BBC Mundo (29.1.2020).

36 João Fellet: "Evangélicos fazem ofensiva para dominar política externa do Brasil para África", BBC News Brasil (23.12.2019).
} 
Dois partidos são importantes dentro da FPE por seu caráter religioso: o Partido Social Cristão (PSC) e o Partido Republicano Brasileiro (PRB). Enquanto o PSC não pode ser associado necessariamente a um credo religioso, o PRB sim pode ser associado diretamente à Igreja Universal do Reino de Deus. No entanto, apesar de seu vínculo com a IURD, o PRB não pretende ser uma associação de seus deputados com a religião, mas é mais aberto, podendo defender medidas como a interrupção da gravidez. Sua ambiguidade ideológica Ihe permite estabelecer alianças mais amplias, como por exemplo com o PT e o PSDB de São Paulo; diferentemente do PSC que, capitaneado por Pastor Everaldo, leva adiante uma agenda claramente conservadora. ${ }^{37}$

\section{OS LÍDERES DA FRENTE PARLAMENTAR EVANGÉLICA: DA ALIANÇA COM O PT AO BOLSONARO}

A formação da Frente Parlamentar Evangélica se deu em 2003. Com o tempo, a FPE foi elegendo políticos que tivessem conhecimentos em Direito para usá-los no plano legislativo a favor da agenda promovida por esta frente parlamentar. ${ }^{38}$ A comissão do Congresso onde a FPE busca ter mais integrantes é a Ciência e Tecnologia, donde se dão as concessões de rádio e televisão, consideradas estratégicas pelas igrejas evangélicas. Os grupos evangélicos, que em 1999 contavam com ao redor de 46 deputados, têm atualmente 195 deputados e 8 senadores. ${ }^{39}$ As igrejas têm "isenção tributaria" no Brasil, e as tentativas de cobrar impostos das mesmas não conseguiram avançar no Congresso pela ação desta bancada. ${ }^{40}$

Vários dos políticos da FPE aparecem ligados em algum momento de sua trajetória a Anthony Garotinho, ex-governador do Rio de Janeiro, de religião evangélica e um dos primeiros políticos promotores do culto em nível de grande escala. "Os pastores circulavam à vontade pelos escalões do Governo. Assisti uma espécie de predicação do governador Garotinho pela TV e fiquei impressionado. Poderia dizer que sua vocação é a de pastor

\footnotetext{
37 Vinicius Magalhães Valle: "Direita religiosa e partidos políticos no Brasil: os casos do PRB e do PSC", Teoria e Cultura, vol. 13, núm. 2 (2018).

38 Janine Trevisan: "A Frente Parlamentar Evangélica: Força política no estado laico brasileiro", Numen, vol. 16, núm. 1 (2013).

39 "Frente Parlamentar Evangélica do Congresso Nacional", Câmara Legislativa Brasil (17.4.2019) e "Quando fé e política se aproximam", O Globo (19.12.1999).

40 Mónica Bergamo: "Bolsonaro deve discutir reforma tributária com lideranças evangélicas", Folha de São Paulo (6.8.2019).
} 
porque um governante não pode se expor dessa forma", ${ }^{41}$ destacava em 1999 Lionel Brizola, presidente do Partido Democrático Trabalhista (PDT), partido do então governador do Rio. Garotinho foi candidato pelo Partido Socialista Brasileiro (PSB) à presidência em 2002, atraiu um número importante de lideranças evangélicas à sua candidatura e teve um bom desempenho eleitoral, ficando em terceiro lugar com 15 milhões de votos no primeiro turno.

Um dos principais articuladores da FPE é o deputado pelo Rio de Janeiro Sóstenes Cavalcante, que representa dentro do Congresso o pastor Silas Malafaia. Cavalcante era seu diretor de eventos ${ }^{42}$ e pertence à Assembleia de Deus Vitória em Cristo. Previamente tinha atuado como assessor do deputado federal do PT, Lindbergh Farias, ${ }^{43}$ e durante um tempo militou no Partido Social Democrático (PSD). Atualmente, forma parte do partido Democratas (DEM), que é o herdeiro do Partido da Frente Liberal (PFL), que por sua vez é herdeiro da Aliança de Renovação Nacional (ARENA), o partido oficial da ditadura (19641985). Este partido se encontra atualmente alinhado com o Governo de Bolsonaro e Rodrigo Maia, um dos principais líderes do mesmo, é o presidente da Câmara dos Deputados.

Cavalcante foi presidente da Comissão Especial que analisa o Estatuto da Família, que defende a ideia de que a "família" se encontra constituída exclusivamente pelo pai e a mãe a partir de uma visão tradicional. Outro dos projetos que impulsiona é a redução da idade de imputabilidade. Durante a votação do impeachment a Dilma Rousseff, participou da campanha "Tchau, querida" que promovia sua destituição através do Congresso.

Uma das emendas defendidas por Cavalcante se refere à implementação do projeto Escola Sem Partido, apresentado pelas deputadas Bia Kicis e Carla Zambelli do Partido Social Liberal (PSL). Um dos aspectos promovidos por este projeto assinala que "o Poder Público não se imiscuirá no processo de maturação sexual dos alunos nem permitirá nenhuma forma de dogmatismo ou proselitismo na abordagem das questões de gênero" e "o Professor não se aproveitará da audiência cativa dos alunos para promover seus interesses, opiniões, concepções ou preferências ideológicas, religiosas, morais, políticas

\footnotetext{
41 "Quando fé e política se aproximam", o. cit.

42 "Força evangélica", O Fluminense (2.4.2014).

43 "Que confusão", O Fluminense (29.4.2014).
} 
e partidárias". 44 Para Cavalcante, na educação, o mais importante é "preservar as famílias" e neste sentido se encontra alinhado com o discurso de Bolsonaro no Palácio do Planalto.

Durante as eleições presidenciais de 2018, segundo Cavalcante, os massivos protestos de mulheres que protagonizaram o \#EleNão ajudaram à vitória do ex-capitão do Exército, posto que os artistas que participaram "estavam muito desentoados com as donas de casa, com o verdadeiro reflexo da mulher brasileira". ${ }^{45}$ Deste modo, Cavalcante identifica a "verdadeira" mulher brasileira com a "dona de casa", evocando uma visão tradicional sobre o papel feminino na sociedade.

Outro dos aspectos promovidos por Cavalcante é o traslado da embaixada do Brasil em Israel de Tel Aviv a Jerusalém -igual ao que fez Donald Trump- como forma de reconhecimento desta última como capital: "Israel é um termômetro dos sinais do que está escrito no Apocalipse. Nossa fé crê nisso. A transferência da embaixada diz respeito a isso. Para nós, todo o cenário será preparado para o Armagedom, como foi descrito no Apocalipse, e o lugar do Armagedom será a cidade de Jerusalém". ${ }^{6}$ Este constitui um ponto forte da agenda evangélica reclamado a Bolsonaro.

Outro importante personagem desta bancada é o Pastor Everaldo, que pertence à Assembleia de Deus Madureira. Começou na política como assistente de Anthony Garotinho, quando era governador do Rio de Janeiro, e então foi subsecretário civil do governo estadual. Em campanha, Everaldo levou Garotinho a falar diante mais de cem mil pessoas em vinte eventos evangélicos fora do Rio de Janeiro para promover as aspirações presidenciais deste último. ${ }^{47}$ Neste período, Everaldo comandava do governo do Rio o programa Cheque Cidadão, que distribuiu por mês vinte e sete mil cheques de cem reais para famílias pobres: $84 \%$ deste montante ia para famílias evangélicas, segundo a revista Istoé. ${ }^{48}$

Em 2003, Everaldo se afiliou ao PSC. ${ }^{49}$ Em 2010, ajudou na coordenação evangélica da campanha de Dilma Rousseff. ${ }^{50}$ Em 2013, um ponto de colisão entre o PT e a bancada evangélica foi a ocupação da presidência da Comissão de Direitos Humanos por parte do

\footnotetext{
44 Projeto de lei, apresentado pela diputada Bia Kicis, para a institucionalização do programa Escola Sem Partido ao Congresso do Brasil.

45 Anna Virginia Balloussier: “Patriota' e 'da família'...”, o. cit.

46 André Duchiade: "Frente evangélica apoia Israel por crença na Apocalipse e na volta de Cristo”, O Globo (6.1.2019).

47 “'PDT do G' pede passagem”, Jornal do Brasil (20.2.2000).

48 "PT pede criação de CPI", Jornal do Brasil (26.4.2000).

49 Grasielle Castro: “Aliado de Garotinho”, Correio Braziliense (8.4.2014).

50 Grasielle Castro: “Evangélico busca apoio fora das igrejas”, Correio Braziliense (20.10.2013).
} 
pastor conservador Marco Feliciano. Aquele fato materializou de forma explícita o choque de valores entre a agenda cultural conservadora evangélica e a agenda progressista do PT em matéria de gênero e direitos humanos, ao expressar os limites dessa aliança pragmática. A decisão da bancada evangélica de romper sua aliança com o Governo de Dilma Rousseff se produziu no mesmo contexto em que se realizaram as manifestações de junho de 2013, quando a popularidade da mandatária caiu ao redor de 40 pontos em sua aprovação.

Naquele momento, Everaldo, que havia formado parte do apoio no Congresso a Lula e Dilma, protestou pelos ataques que recebia Feliciano do PT: "Durante seus dois mandatos, fomos um dos partidos mais fieis da base aliada", declaró quando era vicepresidente do PSC. ${ }^{51}$ E frente à decisão em 2013 do Conselho Nacional de Justiça para regulamentar o casamento entre pessoas do mesmo sexo, Everaldo expressou sua rejeição à medida ao assinalar que "nós defendemos a família conforme está na Constituição brasileira: homem e mulher". 52

O pastor havia disputado a presidência pelo PSC em 2014 com o slogan "Privatiza tudo!". 53 Em 2014, no segundo turno, declarou o seu apoio a Aécio Neves porque considerava que "nunca houve tanta corrupção", em referência aos governos do PT. ${ }^{4}$ Naquele mesmo ano, frente à aparição das acusações de corrupção na principal empresa petroleira estatal, Everaldo havia assinalado que "O petróleo é nosso, mas a Petrobrás, hoje, não é nossa. A empresa é um foco de corrupção e tem uma dívida astronômica. Tudo o que for possível vamos passar para a iniciativa privada". ${ }^{55}$ "Todas as empresas que for possível transferir para as empresas privadas, vou transferir". 56 "O Estado está agigantado hoje, aparelhado, é um foco de corrupção. A família brasileira trabalha hoje mais de cento e cinquenta dias por ano para pagar impostos. O Estado gasta mais do que arrecada e a dívida vai aumentar. Vamos diminuir o número de ministérios", assinalava em um debate televisivo prévio à eleição. ${ }^{57}$ Neste sentido, foi um precursor do discurso de Paulo Guedes, ministro da Economia de Bolsonaro, que associa o Estado com a corrupção e defende as

\footnotetext{
51 Helena Mader: "Clima de confronto", Correio Braziliense (27.03.2013).

52 Étore Medeiros e Leandro Kleber: "PSC contra o casamento gay", Correio Braziliense (22.05.2013).

53 Camila Rocha e Leo Puglia: "Os ideólogos de Jair Bolsonaro", Le Monde Diplomatique Brasil (31.01.2019).

${ }^{54}$ André Shalders: "O embarque de Everaldo", Correio Braziliense (09.10.2014).

55 Maria Clara Prates: "Everaldo promete onda de privatizações", Correio Braziliense (20.08.2014).

56 "Eleições 2014: entrevista com Pastor Everaldo", O Estado de São Paulo (20.08.2014).

57 Amanda Almeida, André Shalders e Diego Amorim: "Debate vira arena para ataques mútuos", Correio Braziliense (17.09.2014).
} 
privatizações como forma de "eliminar" este problema. Por sua vez, vemos como um dos principais pontos da agenda evangélica tem a ver com as denúncias moralistas sobre a corrupção.

O lançamento eleitoral de Everaldo se baseou na crítica ao Governo de Dilma Rousseff em matéria econômica e política. 58 "Desde 2011, nós sabíamos que teríamos um candidato à presidência. Isso forma parte do programa de expansão do partido", ${ }^{59}$ declarava Everaldo referindo-se ao PSC. Everaldo representou uma primeira união entre o conservadorismo moral religioso e o neoliberalismo econômico que logo se cristalizaria na candidatura presidencial de Bolsonaro em 2018. ${ }^{60}$ Neste sentido, conjugava dois aspectos centrais do programa eleitoral do ex-capitão já em 2014, quando foi candidato à presidência.

Everaldo batizou Bolsonaro segundo o credo evangélico em Israel e foi presidente do PSC. A família Bolsonaro havia se desfiliado do PSC -com a exceção do vereador do Río, Carlos Bolsonaro- por não contar com o aval deste partido para a candidatura presidencial do ex-capitão. Finalmente, a família Bolsonaro desembarcou no Partido Social Liberal (PSL) do empresário Luciano Bivar. No entanto, como presidente do PSC, Everaldo destacou o seu apoio a Bolsonaro no segundo turno de 2018.

Um importante líder evangélico é Hidekazu Takayama, que foi coordenador até 2018 da bancada evangélica e é parte atualmente da estrutura partidária do PSC. Frente às críticas a Feliciano, que presidia a Comissão de Direitos Humanos, Takayama explicou em 2013 que "podemos colocar dois, três e até quatro milhões de pessoas na porta do Congresso para dizer que só o senhor é Deus, e esta nação é cristã". ${ }^{61}$ A enunciação de "cristãos" como sinônimo de evangélicos por parte destes líderes é uma tática discursiva utilizada como forma de representar no imaginário da nação uma maioria. ${ }^{62}$

Em trinta anos de vida pública, Takayama passou por seis partidos: PMDB, PFL, PTB, PSB, PAN e PSC. ${ }^{63}$ Durante o primeiro Governo de Lula, como muitos deputados

\footnotetext{
58 Vinicius Magalhães Valle: "Direita religiosa e partidos políticos no Brasil: os casos do PRB e do PSC". Teoria e Cultura, vol. 13, núm. 2 (2018).

59 Grasielle Castro: "Evangélico busca apoio fora das igrejas", Correio Braziliense (20.10.2013).

60 Camila Rocha: “'Conservadorismo fala mais alto que liberais a base de Bolsonaro', diz pesquisadora”, $O$ Estado de São Paulo (10.2.2019).

61 Amanda Almeida e Étore Medeiros: "São 12 milhões de fiéis e de eleitores", Correio Braziliense (9.4.2013).

62 Anna Virginia Balloussier: "A Marcha para Jesus e o que querem os evangélicos", Café da Manhã, Folha de São Paulo, podcast (21.06.2019).

63 "Gazeta entrevista o deputado Takayama pré-candidato ao Senado", Gazeta do Povo - Paraná (15.5.2018). Disponível em youtube.com
} 
evangélicos, enquanto formava parte do PMDB, Takayama estava alinhado com o Planalto, e viajava no avião presidencial. ${ }^{64}$

Takayama é oriundo de Curitiba, Paraná, onde começou como vereador, para logo ter dois mandatos como deputado estadual. Foi a Brasília enviado pelas igrejas do Paraná para promover leis favoráveis ao culto evangélico, ${ }^{65}$ onde teve quatro mandatos como deputado federal. O pastor considera que "estamos em uma encruzilhada com 'ideologias de gênero' que ferem uma nação eminentemente cristã, de católicos e evangélicos, que não querem uma mudança radical com o aborto e a disseminação das drogas". "A base de minha ida ao Senado é defender um pensamento cristão". "Não podemos aceitar a ditadura de uma minoria com o rótulo de progressismo". Takayama se atribui ser o criador da bancada evangélica.

Sobre a base de interpretações de preceitos bíblicos, Takayama justifica o patriarcado e uma visão conservadora sobre as identidades de gênero na sociedade. "Na Bíblia, Deus deve dar direção a uma família, e a família está constituida pelo homem como chefe, essa é uma forma de cristianismo". Em 2015, na votação do Estatuto da Família, Takayama declarou que "não se pode aceitar que um homem com outro homem faz uma família". ${ }^{66}$ Neste mesmo sentido, em 2017, Takayama defendia que a prioridade da frente seria 'lutar contra esse 'tiroteio' orquestrado pelos ateus e 'esquerdopatas', contra nossas crianças". 67

O caso do pastor Marco Feliciano é emblemático pela importância que teve ao presidir a Comissão de Dereitos Humanos, fato que foi vivido como uma grande vitória e avanço político por parte da FPE. Eduardo Bolsonaro, o filho do atual presidente, ingressou no Congresso em 2014 pela mão de uma lista com Feliciano pelo PSC, em que este último obteve 398000 votos em 2014. ${ }^{68}$ Quando foi designado para a presidência da Comissão de Direitos Humanos em 2013 e questionado por militantes de esquerda que pediam sua renúncia, um grupo evangélico abriu um cartaz frente às câmeras, com o texto " $E$ se Jesus renunciasse? O que seria do mundo? Marco Feliciano, não renuncie, estamos contigo. Povo Cristão". 69

\footnotetext{
64 "Lula concorda em retaliar aliados que assinarem CPI", Jornal do Brasil (24.5.2005).

65 "Biografia", Cristo Vive. Evangelismo Mundial (página de internet sem data). Disponível em cristovive.inf.br 66 "Avança estatuto que exclui união gay de definição de família", Folha de São Paulo (25.09.2015).

67 "Bancada evangélica mira 'direitos humanos", Folha de São Paulo (29.10.2017).

68 Anna Virginia Balloussier: "Evangélicos apostam em 'distritão' para crescer", Folha de São Paulo (17.8.2017).

69 Isabel Braga: "PSC anuncia que Feliciano fica na Comissão de Direitos Humanos", O Globo (26.3.2013).
} 
Em 2016, durante o processo de impeachment de Dilma Rousseff, Feliciano foi líder do PSC na Câmera de Deputados e votou a favor da destituição. Quando dessa destituição, assinalou: "Alguns remédios terão que ser aplicados no nosso país e serão remédios amargos, porque nosso país está quebrado e a economia está quebrada", ${ }^{70}$ preparando o terreno para as reformas de austeridade econômica do presidente Michel Temer. Já na presidência, durante um congresso evangélico, Bolsonaro saudou Feliciano como um "velho companheiro de lutas na Comissão de Direitos Humanos na defesa da família tradicional". ${ }^{71}$

Com efeito, Bolsonaro havia defendido Feliciano em 2013 das críticas quando o pastor se encontrava à frente da comissão. "Como capitão do Exército, sou um soldado de Feliciano", declarou então Bolsonaro, que era membro suplente da comissão: "Não sinto mais aquele odor delicado que havia aqui dentro e aquele peso nas costelas. Aqui, que era uma comissão orientada contra os interesses humanos, contra os interesses das crianças e contra os interesses da família. Agora, esta comissão está no caminho correto. Parabéns, Feliciano". ${ }^{72}$

Bolsonaro se sentou na primeira sessão da comissão ao lado de Feliciano e anunciou que a "festa gay" havia terminado. ${ }^{73}$ Aldo Zaiden, assessor de Saúde Mental do Ministério de Saúde, fez um discurso na comissão em que assinalava que "os direitos humanos vivem um retrocesso", mas Bolsonaro o interrompeu e lhe espetó: "O senhor deve restringir-se ao tema da audiência pública. Não faça um discurso". ${ }^{74}$ Por sua vez, frente aos ataques que sofria, Feliciano denunciou então:

Recebí uma mensagem de pureza e santidade. Vou falar como profeta. Me dá pavor entrar na Câmara dos Deputados deste país e saber como Satanás está infiltrado no Governo brasileiro, mas não só no Governo brasileiro, mas no governo do mundo. Satanás recrutou homens e mulheres, e a Igreja não se deu conta [...] Satanás levantou o seu ativismo neste país, existe uma ação de Satanás contra a família, dentro deste nosso Governo de esquerda. ${ }^{75}$

\footnotetext{
70 "Marco Feliciano fala sobre o impeachment de Dilma", Gospel + (1.9.2016).

${ }^{71}$ Mônica Bergamo: "Bolsonaro elege Feliciano, que pediu impeachment de Mourão, como interlocutor", Folha de São Paulo (3.5.2019).

72 Fabiano Costa e Nathalia Passarinho: "Sou um soldado do Feliciano', afirma deputado Jair Bolsonaro", G1 Globo (27.3.2013).

73 Evandro Éboli: "Na primeira reunião, tumulto e palavra cassada em comissão", O Globo (14.3.2013).

74 Evandro Éboli: "Pastor resiste a pressão", O Globo (21.3.2013).

75 Isabel Braga e Evando Éboli: "Pastor liga governo a Satanás, mas pede ajuda para conter petistas", $O$ Globo (15.3.2013).
} 
Após buscar que duas jovens que se beijavam em São Sebastião (São Paulo) fossem encarceradas, Feliciano aprovou um projeto na comissão que permitia excluir as minorias sexuais dos cultos religiosos e a possibilidade de que os pastores se negassem a sancionar o casamento entre personas do mesmo sexo. ${ }^{76}$ Atualmente, Feliciano é vice-líder do Governo na Câmara dos Deputados, e um dos principais enlaces entre o presidente e a bancada evangélica.

O atual coordenador da FPE, Silas Câmara é um pastor da Assembleia de Deus e fez carreira política no estado do Amazonas. Ali sua família conta com uma concessão de radiodifusão e é proprietária da Rede Boas Novas de Televisão. ${ }^{77}$ Este canal televisivo exibe programas evangélicos em toda a sua programação. ${ }^{78}$ Seus irmãos, Jonatas e Samuel foram presidentes da Igreja Mãe da Assembleia de Deus naquele estado. ${ }^{79}$ Jonatas, atual presidente da Assembleia de Deus do Amazonas, pediu a seus fieis que assinem a lista de apoio para a criação do novo partido de Bolsonaro, Aliança pelo Brasil. Esta mesma prática foi realizada pelo reverendo Emerson Patriota, da Igreja Presbiteriana Central de Londrina, que "desafiou" os fiéis pedindo assinaturas para o novo partido durante o culto. ${ }^{80}$ Uma das fontes do poder evangélico são as construções de poder familiar e de clã, tal como se deu no caso dos Câmara. ${ }^{81}$

Silas foi deputado federal pelo Amazonas, cargo que desempenhou por cinco mandatos consecutivos desde 1998. Foi eleito por primeira vez pelo Partido Liberal (PL) com 38.427 votos, ${ }^{82}$ mas ao assumir no Congresso, passou para o PFL, denunciando que o PL se encontrava dominado pela Igreja Universal do Reino de Deus. ${ }^{83}$ Então passou para o PTB, onde foi votado principalmente pelos seguidores de sua igreja pentecostal, a Assembleia de Deus. ${ }^{84}$ Também foi membro de uma comissão da Câmara dos Deputados

76 "Feliciano quer expulsar gays de cultos", O Globo (17.10.2013).

77 Ou seja, trata-se de um deputado que aproveitou as condições do "coronelismo eletrônico" (conceito acunhado por Venício Lima), processo através do qual Antônio Carlos Magalhães, ministro de Comunicações do Governo de José Sarney, brindou aos deputados concessões de radiodifusão.

78 Daniel Castro: "Outro Canal: Governo dá canal em SP a evangélicos", Folha de São Paulo (27.9.2003).

79 "Evangélicos", Jornal do Commercio Amazonas (7.11.1997).

${ }^{80}$ Agencia Estado: "Em culto, pastor pede que fiéis assinem apoio a partido de Bolsonaro", Correio Braziliense (29.1.2020).

81 Tatiane dos Santos Duarte: “'A casa dos ímpios se desfará, mas a tenda dos retos florescerá': a participação da Frente Parlamentar Evangélica no legislativo brasileiro", dissertação Mestrado em Antropologia Social, Universidade de Brasília (2011).

82 "Federais eleitos", Jornal do Commercio Amazonas (6.10.1998) e "Os números finais da eleição", Jornal do Commercio Amazonas (10.10.1998).

83 "Ademir Ramos prega paz e cobra compromissos", Jornal do Commercio Amazonas (23.4.1999) e "Alfredo Nascimento disputa PL com Eduardo Braga em Brasília", Jornal do Commercio Amazonas (9.6.1999).

${ }^{84}$ Roberto Samora: "Garotinho leva 30 mil a culto no AM", Folha de São Paulo (22.11.1999). 
considerada estratégica pelos evangélicos: Ciência e Tecnologia. ${ }^{85}$ Então passou para o PRB em 2016. ${ }^{86}$

Em abril de 2017, votou a favor da reforma trabalhista, mostrando assim afinidades com o rumo pró mercado que tomou o país desde o impeachment de Dilma Rousseff em abril de 2016 e sua substituição pelo vice-presidente conservador Michel Temer. Votou duas vezes a favor de arquivar as denúncias de corrupção contra o então presidente, as quais poderiam ter terminado na destituição de seu cargo.

Ao ser eleito como o coordenador do FPE durante o Governo de Jair Bolsonaro, Silas Câmara chamou a construir uma agenda Brasil+cristão+informado e preparado para levar adiante no Congresso.

A pastora Damares Alves, ministra da Mulher, Família e Direitos Humanos do Goveno, disse a Silas que "estamos propondo, deputado, aquele grande sonho nosso de uma contrarrevolução cultural no Brasil. Uma releitura dos direitos humanos" acorde com uma visão conservadora evangélica. ${ }^{87} \mathrm{~A}$ figura da ministra não deixa de ser significativa, ao tratar-se da única que possui uma aprovação mais alta entre os pobres do que entre os ricos dentro do elenco governamental e ser a segunda melhor avaliada do Governo, particularmente entre os neopentecostais. Sua agenda conservadora inclui uma firme oposição ao aborto e a criação de uma linha telefônica de denúncias para que os padres denunciem os docentes que nas salas aulas "atentem contra a moral, a religião e a ética da família". ${ }^{88}$ Outrossim, a promoção da abstinência sexual entre os jovens para enfrentar a gravidez dos adolescentes.

\section{A AGENDA COMUM ENTRE BOLSONARO E OS EVANGÉLICOS}

A partir da análise destes líderes, pudemos observar que o bloco possui uma agenda política própria. A mesma se encontra definida pelo Estatuto do Nascituro -que supõe conceber a vida e estender os Direitos da Criança desde o começo da gravidez, em oposição ao aborto- e o Estatuto da Família, que define esta como constituída apenas pelo

\footnotetext{
85 "Proibição de aluguel de programas na TV irrita evangélicos", Folha de São Paulo (4.6.2012).

86 "Silas Câmara troca PSD de Omar por PRB", No Amazonas é Assim (3.3.2016).

87 Michael Caceres: "Damares Alves propõe 'contrarrevolução cultural' com apoio da Bancada Evangélica", Gospel Prime (31.7.2019).

88 Mônica Bergamo: "Damares abre Disque 100 para professores denunciarem pais", Folha de São Paulo (9.12.2019).
} 
homem e a mulher. Também se encontram o projeto de "reversão da homossexualidade" e Escola Sem Partido, um projeto que denuncia o "doutrinamento da esquerda" nas escolas e universidades e busca perseguir, estigmatizar e afastar os professores que falem de política com uma visão progressista na sala de aula. Outro dos eixos fundamentais da FPE é a demanda pelo traslado da embaixada do Brasil em Israel de Tel Aviv a Jerusalém.

Há eixos centrais que unificam o discurso dos líderes evangélicos em torno a uma agenda que foi adotada por Bolsonaro em 2018, pegando de surpresa o progressismo. Estes eixos são: A) Uma concepção conservadora da família como base da sociedade, que garante papeis estáticos para o homem e a mulher e não admite outras identidades sexuais. Isto implica uma visão patriarcal do homem como um ativo "chefe de família" e a mulher num lugar passivo como "dona de casa". B) Uma rejeição a qualquer modificação nestes papeis como um ataque à família brasileira, à mulher e às crianças. $\mathrm{C}$ ) No contexto de um descrédito da classe política por acusações de corrupção, uma visão neoliberal na economia e conservadora nos costumes que permite articulações como a candidatura de Pastor Everaldo e Bolsonaro. D) A ideia de que a Nação é predominantemente cristã e, portanto, deve adaptar sua legislação às necessidades dessa maioria.

Deste modo, busca-se modificar garantias fundamentais da Constituição de 1988, como a livre escolha religiosa e sexual, assim como a igualdade de gênero. Estas são percebidas como uma afronta aos valores cristãos. Por sua vez, os políticos evangélicos pretendem deter políticas que a esquerda e o progressismo querem aprovar, como o aborto.

As seguintes conexões dão a pauta da união que existe entre um programa de costumes conservadores com o livre mercado: o deputado Sóstenes Cavalcante forma parte da Frente Parlamentar pelo Livre Mercado coordenado pelo deputado federal do Movimento Brasil Livre, ${ }^{89}$ Kim Kataguiri, que forma parte da FPE. Há vários deputados que formam parte de ambas as frentes: Alan Rick, Sóstenes Cavalcante, Silas Câmara, Celso Russomanno, Pastor Sargento Isidório, Kim Kataguiri, Luis Philippe de Orleans e Bragança, entre outros. ${ }^{90}$ Por sua vez, a maioria da FPE votou a favor da reforma da previdência no

89 O Movimento Brasil Libre (MBL) é um grupo juvenil de ideologia neoliberal que surgiu em São Paulo no contexto dos grandes protestos que ocorreram em junho de 2013 em todo o país, jornadas nas que demandavam uma maior e melhor presença estatal e outras pautas heterogêneas. As jornadas de junho haviam surgido inicialmente a partir dos protestos do movimento horizontal de esquerda Passe Livre. Uma vez comprovado o potencial de convocação das formas horizontais e juvenis deste último movimento, surgiu o MBL, que começou a imitar este tipo de convocação na busca de atrair apoiadores para o outro espectro ideológico. O MBL foi crescendo, desempenhando um papel protagonista nos protestos do ciclo 2015-2016 que conduziram à queda da presidenta Dilma Rousseff, submetida finalmente a um julgamento político pouco transparente no Congresso.

90 “Frente Parlamentar pelo Livre Mercado", Câmara Legislativa do Brasil (24.4.2019). 
Congresso, uma das principais medidas defendidas pelo ministro da economia neoliberal, Paulo Guedes. ${ }^{91}$

Isto cristaliza a união entre livre mercado e costumes conservadores que havia materializado a candidatura de Pastor Everaldo em 2014 e ingressa no Estado com a chegada à presidência de Bolsonaro em janeiro de 2019.

No contexto de crise econômica, social e política do Brasil, o discurso e a atuação como intermediários dos líderes evangélicos foi crucial para construir o vinculo entre neoliberalismo e conservadorismo que hoje tem carnadura estatal no Governo de Bolsonaro. O moralismo religioso opera assim como um componente central para a união entre neoliberalismo e autoritarismo, que se apresenta como uma restituição da ordem no contexto de crise política e econômica que vive o Brasil. Assim, apresenta-se uma convergência entre as pautas principais dos pastores evangélicos no Congresso e a democracia messiânica plebiscitária defendida por Bolsonaro.

A importância da rejeição que Feliciano provocou como presidente da Comissão de Direitos Humanos foi o ponto de emergência do divórcio entre o PT e a FPE, assim como também a candidatura de Pastor Everaldo à presidência em 2014. Estes acontecimentos foram fundamentais e uma condição de possibilidade para a articulação bolsonarista que se produziu em 2018.

O vínculo privilegiado de Bolsonaro com Marco Feliciano na presidência da Comissão de Direitos Humanos da Câmara de Deputados contra os "esquerdistas" foi importante para o nascimento de uma "nova direita". Estes fatos cristalizaram a ruptura entre o PT e a FPE. Por sua vez, revela o crucial papel cumprido pelo vínculo entre Feliciano e Bolsonaro para a afirmação de ambos em uma agenda conservadora e que coloca a esquerda como inimiga da nação. Por isso, consideramos que a chegada dos evangélicos ao Estado é algo que veio para ficar e dará sustentação ao presidente do Brasil.

Esta análise também desmente algumas crenças da imprensa e dos setores progressistas sobre a factibilidade de que seja realizado um impeachment de Bolsonaro e de que o ex-capitão do Exercito seja substituído pelo vice-presidente Hamilton Mourão. Se se considera que $89 \%$ da FPE votou a favor do impeachment de Rousseff em 2016, e tem ao redor de duzentos deputados numa Câmara de quinhentos e treze, onde se precisa de uma maioria para aprovar o julgamento político, é evidente que o forte apoio dos principais

91 "Veja como votaram os deputados evangélicos na reforma da Previdência", JM Notícia (11.7.2019). 
líderes da FPE e a adoção presidencial de uma agenda evangélica dificultarão essa possibilidade. Enquanto o presidente continua numa tendência à declinação em sua popularidade, estes setores aumentam proporcionalmente a sua importância para a sustentação do Governo, ganhando espaço e influência.

\title{
REFERÊNCIAS
}

GOLDSTEIN, Ariel. Jair Bolsonaro y los políticos evangélicos. In: GOLDSTEIN, Ariel. Poder Evangélico. Cómo los grupos religiosos están copando la política en América. Buenos Aires: Marea, 2020.

\section{NOTAS}

\section{TÍTULO DA OBRA}

JAIR BOLSONARO E OS POLÍTICOS EVANGÉLICOS

\author{
AUTOR \\ Ariel Goldstein \\ Universidade de Buenos Aires, Buenos Aires, Argentina \\ arielgoldstein@hotmail.com \\ (D) https://orcid.org/0000-0002-0105-4428

\section{TRADUTOR} \\ Flavio Pereira \\ Universidade de São Paulo (USP), São Paulo, Brasil \\ poliglotta@gmail.com \\ iD https://orcid.org/0000-0001-5922-6360
}

\section{LICENÇA DE USO}

Os autores cedem à Em Tese os direitos exclusivos de primeira publicação, com o trabalho simultaneamente licenciado sob a Licença Creative Commons Attribution 4.0 Internacional (CC BY). Esta licença permite que terceiros remixem, adaptem e criem a partir do trabalho publicado, atribuindo o devido crédito de autoria e publicação inicial neste periódico. Os autores têm autorização para assumir contratos adicionais separadamente, para distribuição não exclusiva da versão do trabalho publicada neste periódico (ex.: publicar em repositório institucional, em site pessoal, publicar uma tradução, ou como capítulo de livro), com reconhecimento de autoria e publicação inicial neste periódico.

\section{PUBLISHER}

Universidade Federal de Santa Catarina. Programa de Pós-Graduação em Sociologia Política. Publicado no Portal de Periódicos UFSC. As ideias expressadas neste artigo são de responsabilidade de seus autores, não representando, necessariamente, a opinião dos editores ou da universidade.

\section{HISTÓRICO}

Recebido em: 17 de junho de 2021

Aprovado em: 17 de maio de 2021 